See discussions, stats, and author profiles for this publication at: https://www.researchgate.net/publication/341551904

\title{
Experimental test of the communicative value of syllable diversity and syllable switching in the common chiffchaff
}

Article in Animal Behaviour July 2020

DOI: 10.1016/j.anbehav.2020.04.016

\section{CITATIONS}

3 authors, including:

Javier Sierro

Lancaster University

5 PUBLICATIONS 22 CITATIONS

SEE PROFILE
READS

70

Hans Slabbekoorn

Leiden University

238 PUBLICATIONS 8,886 CITATIONS

SEE PROFILE

Some of the authors of this publication are also working on these related projects:

ecology impact windmills View project

Quantifying composition, distribution and intensity of natural and anthropogenic sounds in the Dutch part of the North Sea View project 


\title{
Experimental test of the communicative value of syllable diversity and syllable switching in the common chiffchaff
}

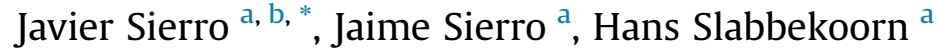 \\ a Behavioural Biology, Institute of Biology, Leiden University, Leiden, the Netherlands \\ ${ }^{\mathrm{b}}$ Lancaster Environment Center, Lancaster University, Lancaster, U.K.
}

\section{A R T I C L E I N F O}

\section{Article history:}

Received 7 December 2019

Initial acceptance 31 January 2020

Final acceptance 5 March 2020

MS number 19-00812R

\section{Keywords:}

acoustic communication

agonistic interactions

birdsong

common chiffchaff

playback experiment

song switching

syllable diversity

syllable switching

\begin{abstract}
All songbirds have their own species-specific song, and vocal variety among individuals of the same species is used for communication. Some aspects of vocal variety have been shown to relate to sender characteristics and thus to convey a potential message to receivers. During playback experiments, individuals show different response patterns, which provide evidence for perception, and thus meaning, of the vocal variety. Here, we tested the impact of two types of vocal variety: syllable diversity and syllable switching in the common chiffchaff, Phylloscopus collybita, in two separate playback experiments. We found that syllable diversity was a relatively fixed trait and that variation among individuals was likely to reflect some male quality triggering responses of different intensity. Higher rates of syllable switching did not elicit different responses but songs after playback showed that it is a dynamic trait, potentially contributing to motivational signalling together with other song parameters. The resolution of analyses in our experiments revealed subtle changes in vocal features over time in unprecedented detail. This approach unveiled an intricate combination of various vocal features during the response that may complement each other during vocal interactions. We believe future studies would benefit from the same resolution, through which one can explore advanced levels in animal communication.
\end{abstract}

(c) 2020 The Association for the Study of Animal Behaviour. Published by Elsevier Ltd. All rights reserved.
Individual vocal diversity in birds has evolved because acoustic variety provides an important means for communication during social interactions (Catchpole \& Slater, 2003; Kroodsma \& Byers, 1991; Searcy \& Andersson, 1986). Elaborate songs have been shown to attract social and sexual partners and deter competitors of the same sex (Searcy \& Andersson, 1986; Collins 2004). Territorial contests among male birds in temperate regions have been especially well studied and singing pays despite probable trade-offs with, for example, time to spend on foraging and elevated predation risk (e.g. Hiebert, Stoddard, \& Arcese, 1989; Leitao, ten Cate, \& Riebel, 2006; Mountjoy \& Lemon, 1991). Many aspects of song have been shown to carry messages about the singers and to affect conspecific responses, and thus to be meaningful to the birds. However, many questions remain about whether song variety contains any message and, if so, whether the birds pay attention to it.

Highly elaborate songs have been considered the vocal equivalent of the peacock's tail, although vocal variety can have many

\footnotetext{
* Correspondence: J. Sierro, Lancaster Environment Center, Lancaster University, Library Avenue, Lancaster, LA1 4YQ U.K.

E-mail address: j.sierro@lancaster.ac.uk (J. Sierro).
}

forms (Searcy \& Andersson, 1986; Kroodsma 2004). The elaboration of a song is generally determined by two main parameters: the diversity of element types used and the rate of switching between those types. Here we use the term diversity to mean the repertoire of different syllable or element types sung in a song. Song or syllable diversity can range from a song with repetitions of a single syllable type to a song in which each syllable is of a different type. The term song or syllable switching refers to the sequence in which the elements are sung, that is, the proportion of repetitive and switching transitions within the song (Kramer, Lemon, \& Morris, 1985; Searcy, Nowicki, \& Hogan, 2000). A transition between two elements that belong to the same type is a repetition whereas a transition between two elements of a different type is a switch. Syllable diversity and syllable switching are inherently correlated to some extent but provide complementary measures of the song composition and way of performance.

Song elaboration in general has been associated with male qualities that are beneficial to females when choosing mates and make competitor males more cautious during a fight (Doutrelant, Blondel, Perret, \& Lambrechts, 2000; Hesler et al., 2012; Pfaff, Zanette, MacDougall-Shackleton, \& MacDougall-Shackleton, 2007). Several possible mechanisms could explain the relationship between song elaboration and individual quality. Variation in 
nutritional stress during early development may limit the formation of fundamental brain structures involved in birdsong (Nowicki, Peters, \& Podos, 1998; Airey et al., 2000; Brumm et al., 2009), which may determine the capacity to learn a large repertoire or the switching rates. Other authors have proposed that song elaboration and singing ability grow with age due to the inherent increase in time available to learn new songs or to gain performance capacity (Balsby, 2000; Galeotti, Saino, Perani, Sacchi, \& Møller, 2001; Gil, Cobb, \& Slater, 2001; Järvi, 1983; Mountjoy \& Lemon, 1995).

Regardless of whether song elaboration is the result of favourable developmental conditions or vocal experience over the bird's life, it could be used to signal the ability to fight or the motivation to escalate into a fight. The ability to fight is assumed to be associated with qualities of the individual such as body size or body condition (Galeotti, Saino, Sacchi, \& Møller, 1997; Hall, Kingma, \& Peters, 2013). Motivation, on the other hand, is probably related to shortterm factors such as the presence of a nearby mate, the quality of resources in dispute or the qualities of the opponent. Fighting ability may be signalled through relatively fixed traits, with low variation within individuals, whereas motivation involves more dynamic song traits that birds flexibly adjust to convey their level of excitement, i.e. singing rate, song overlap, song matching or song switching (Burt, Campbell, \& Beecher, 2001; Kramer et al., 1985; Otter, Ratcliffe, Njegovan, \& Fotheringham, 2002; Szymkowiak \& Kuczyński, 2017; Weary, Krebs, Eddyshaw, McGregor, \& Horn, 1988). Whether song diversity or song switching occurs as a relatively fixed or more dynamic trait has not been tested yet, but can be explored experimentally using playback tests (Catchpole, 1977; McGregor et al., 1992; Ripmeester et al., 2007; Hof \& Podos, 2013).

The song of the chiffchaff, Phylloscopus collybita, provides an excellent opportunity to explore the communicative value of syllable diversity and syllable switching within songs. The name 'chiffchaff' is onomatopoeic and reflects what humans hear in its song: alternations of high- and low-frequency syllables (see Fig. 1a, b, c). Syllables of this species are rapid, downward frequency sweeps with one or more inflection points and they usually have a spectral cluster of energy at a relatively high or low frequency (e.g. Verzijden et al., 2010; Linhart, Jaška, Petrusková, Petrusek, \& Fuchs, 2013). Despite the disyllabic name, individual chiffchaffs usually have a repertoire of three or more syllables. They sing their repertoire in repetitive, switching or highly diverse series. Earlier playback studies have shown that individuals in this species increase the syllable rate during territorial conflicts and that birds singing at high syllable rates are more likely to attack (Linhart et al., 2013). Other studies have shown that longer songs elicit a stronger response in territory holders, but that playback stimulation had no effect on the song length of the responding individuals (Linhart, Slabbekoorn, \& Fuchs, 2012; McGregor, 1988).

In the current study, we tested the communicative value of syllable diversity and syllable switching within songs in the chiffchaff using two independent playback experiments. In experiment 1 , we tested the hypothesis that higher-diversity songs are perceived as a higher threat during territorial conflicts. Thus, we presented territorial males with two song stimuli that differed in the number of syllable types within songs (two versus five). In experiment 2 , we tested the hypothesis that higher switching rates between syllables are perceived as a higher threat during territorial conflicts (Lemon \& Kramer, 1983). The song stimuli differed in syllable switching rates: two syllable types were played in either repeating or fully switching fashion. We used the strength of the behavioural response and the change in song from before to after playback to assess whether the treatment differences were detected and meaningful to the birds. Stronger responses would indicate that responding birds perceived the acoustic variant reflecting a
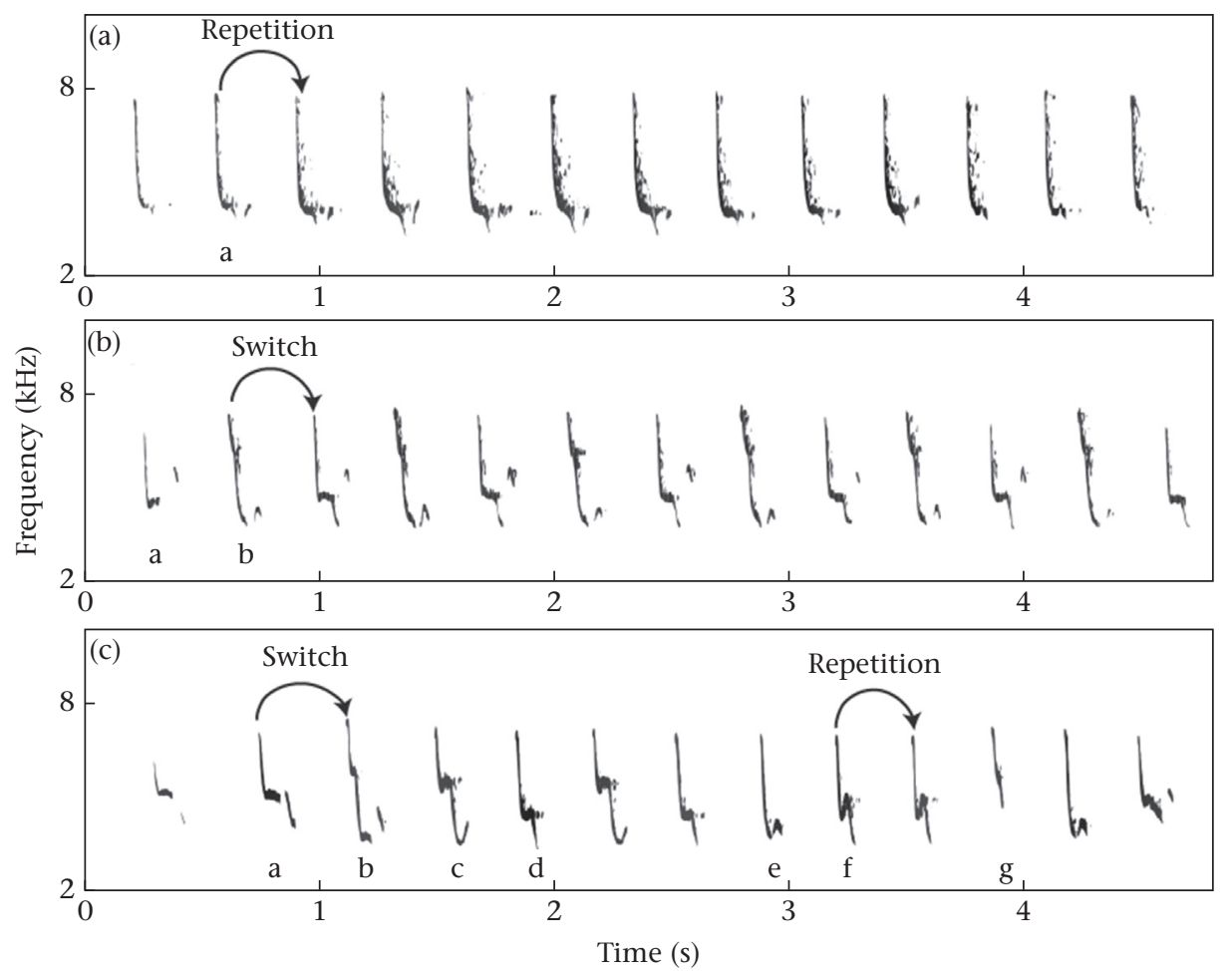

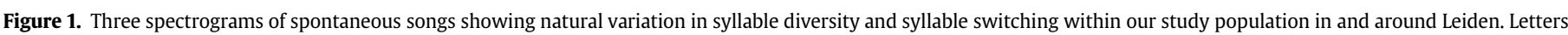

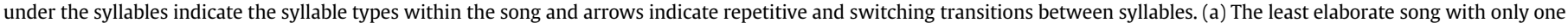

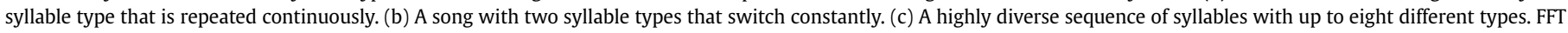
window length 512 samples, window overlap $80 \%$, window type=Hamming. 
stronger or more motivated competitor. The absence or presence of dynamic variation in the vocal response would indicate that birds signalled their ability or their motivation to escalate into a fight with syllable diversity and/or syllable switching.

\section{METHODS}

\section{Model Species, Study Site and Territory Mapping}

The chiffchaff is a small, migratory passerine weighing ca. $8 \mathrm{~g}$ (Bairlein et al., 2006). During the breeding season, from late February to early July, it is widespread over the Western Palearctic region, with a population density that may reach $22-50$ breeding pairs $/ \mathrm{km}^{2}$ (Cramp, 1992; Helbig et al., 1996). In 2014, the singing activity in our study area started in early March as males began to establish breeding territories (Cramp, 1992; Rodrigues, 1996). The study population lived in and around the city of Leiden $\left(52^{\circ} 09^{\prime} 16^{\prime \prime} \mathrm{N}, 4^{\circ} 29^{\prime} 41^{\prime \prime} \mathrm{E}\right)$, in residential areas with a fair number of trees and urban parks.

The birds for this study were not caught or marked, but we avoided double sampling by mapping song posts. Territory fidelity is high during a breeding season (Cramp, 1992; Rodrigues, 1996) and it is therefore possible to avoid mixing up different individuals. During the mapping process and before the playback experiments, we collected audio recordings of spontaneous song in 12 territories. The purpose of these recordings was to estimate the natural variation in both syllable diversity and syllable switching and as a source for the preparation of the playback stimuli. Both the spontaneous recordings and the subsequent playback tests were carried out from 0600 to 1300 hours.

\section{Experimental Design and Playback Methodology}

We conducted two experiments with multiple trials using the same methodology in both. Each experimental trial consisted of the presentation of two playback stimuli to the same individual, allowing us to compare the response of the same bird towards the two treatments. In experiment 1, on the role of syllable diversity, we tested 22 birds and began on 24 April 2014. We began experiment 2 on the role of syllable switching on 23 May and we tested 21 new birds that were different from those in experiment 1 . We controlled for the effect of order with a balanced design, alternating the order of treatment presentation. We carried out the playbacks with an Intertechnik M $130 \mathrm{KX} 4$ speaker with a Monacor IPA-10 amplifier placed inside the territory and a smartphone as digital audio player. We recorded song with a Marantz PMD661 recorder (48 kHz sampling rate and 24-bit depth), together with a Sennheiser ME 67 directional microphone covered with a foam windshield.

Once we detected a bird singing in its territory, we began our test by placing the loudspeaker on the ground (facing upwards) inside the territory, approximately $10 \mathrm{~m}$ away from the singing male. While placing the speaker, we visually delimited a $1 \mathrm{~m}$ perimeter around the speaker, ensuring there was a potential perch within this range. The complete exposure was divided into three phases: preplayback, playback and postplayback. During the preplayback phase, we recorded 10 songs of spontaneous singing (on average for $3 \min 13 \mathrm{~s}, \mathrm{SE}=7.6 \mathrm{~s}, N=43$ ). Then, we proceeded to play the stimulus from the loudspeaker. The postplayback phase began once the playback stimulus had finished and it lasted until the bird sang another 10 songs (on average for $3 \mathrm{~min} 50 \mathrm{~s}$, $\mathrm{SE}=8.1 \mathrm{~s}, N=43$; Linhart et al., 2013). The distance from the bird to the microphone was usually less than $10 \mathrm{~m}$. The next day, we arrived at the same territory at a similar time of day and waited for the individual to sing at the same post. Then, we carried out the second playback test using the complementary treatment.

\section{Stimulus Preparation}

In experiment 1, we tested male responses to songs of high and low syllable diversity. To build the playback stimuli, we first measured the natural variation in syllable diversity within songs from a preliminary sample of spontaneous song of 12 individuals (10 songs per individual). These recordings were collected during the mapping process before we began the experiments. We used Audacity (Mazzoni \& Dannenberg, 2014) to compute spectrograms through an FFT algorithm (window size of 1024 samples, $80 \%$ overlap, Hamming window). Analysis of this sample showed that the natural range of syllable diversity was one to eight syllable types (mean $=3.35, \mathrm{SE}=0.25, N=12$; Fig. 1c). Subsequently, we selected repertoires of five syllable types as the high-diversity treatment and two syllable types as the low-diversity treatment covering a large part of the natural range but avoiding the rare extremes (see Fig. 2).

We used spontaneous songs of 22 males at our study site for the preparation of 22 independent paired stimuli, thereby avoiding pseudoreplication (Kroodsma, 1990; McGregor, 2000). The manipulation of these recordings was done in Audacity (Mazzoni \& Dannenberg, 2014). We always selected syllables from high-quality recordings, which were free of background sounds that could affect playback responses. For each selected syllable, we also included the corresponding syllable interval (the following gap, cf. Linhart et al., 2013). From a single recording we extracted five different syllable types to construct the high-diversity stimulus. All five syllables were pasted together in the same order as they appeared in the original recording. The entire set of five syllables was duplicated to obtain a song 10 syllables long. For the corresponding low-diversity stimulus, we randomly selected two syllable types from the five syllable types of the high-diversity song. The order in which these two syllable types appeared in the low-diversity song was random. Finally, a unique pair of high- and low-diversity stimuli was assigned to each territory.

In experiment 2, we tested the role of syllable switching by comparing responses to songs with high versus low switching rates generated in the same way as in experiment 1. Only two syllable types were chosen to create both stimuli of each pair. For the highswitching stimuli, we designed a song of 10 syllables where both types were continuously alternating. For the low-switching treatment, each syllable type was repeated five times in a repetitive sequence before switching to the second syllable type (Fig. 3). Spontaneous songs of 21 males were processed into unique pairs of stimuli and played back to 21 males.

To make sure the subject had never heard the playback song before, we chose recordings from distant territories (mean $=1.9$, $\mathrm{SE}=0.21 \mathrm{~km}, N=12$ ) in both experiments. The playback songs of both experiments were always 10 syllables long, similar to spontaneous songs ( mean $=11, \mathrm{SE}=0.86$ syllables, $N=12$ ). To build one stimulus a song was copy-pasted 10 times in a row with a constant song gap of $6.33 \mathrm{~s}$, which was the mean song gap from the preliminary sample of spontaneous song (mean $=6.33, \mathrm{SE}=1.50 \mathrm{~s}$, $N=12$ ). As the final step, we applied a high-pass filter at $1500 \mathrm{~Hz}$, normalized all audio tracks and adjusted the speaker to a maximum sound pressure level of $85 \mathrm{~dB}$ at $1 \mathrm{~m}$ from the speaker (American Recorder Technologies, Simi Valley, CA, U.S.A.; SPL-8810, response set FAST and A-weighting).

\section{Song and Behavioural Analyses}

The same two observers carried out all playback tests. During the tests, we measured two aspects of the behavioural response: the latency to counter-sing and the approach response. In all cases, subjects stopped singing during playback and began searching for 


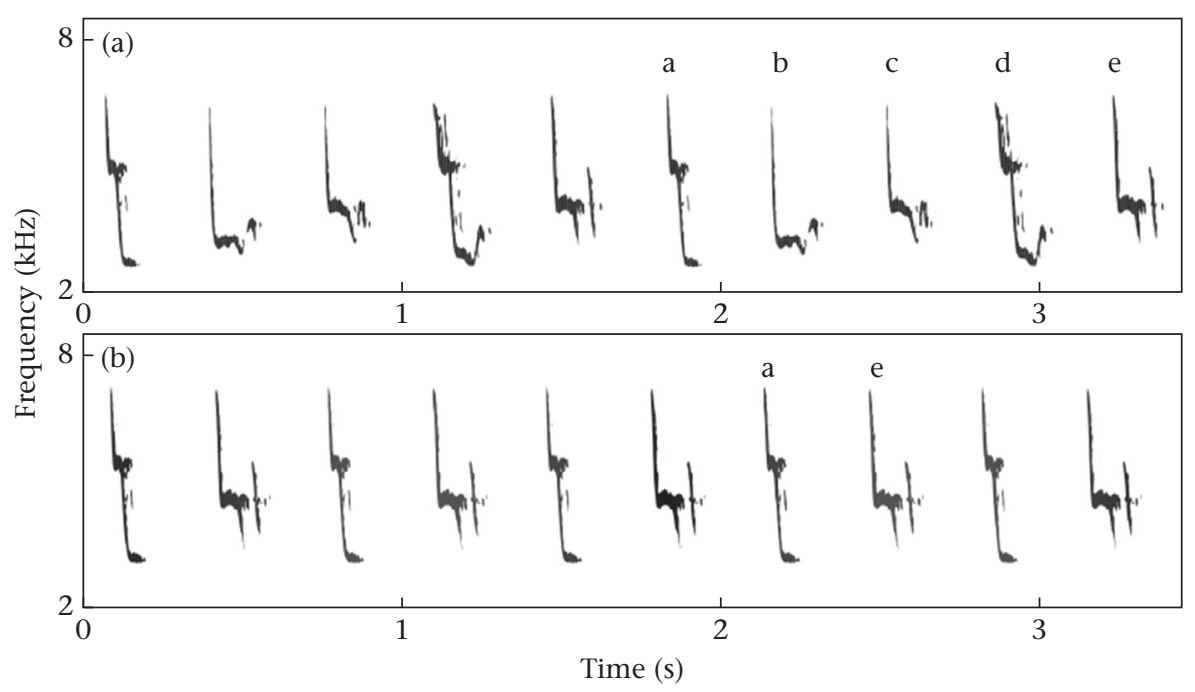

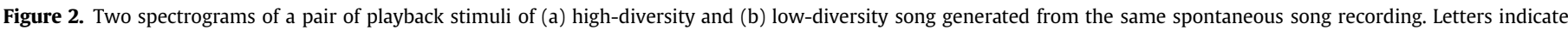
syllable types. FFT window length 512 samples, window overlap $80 \%$, window type=Hamming.

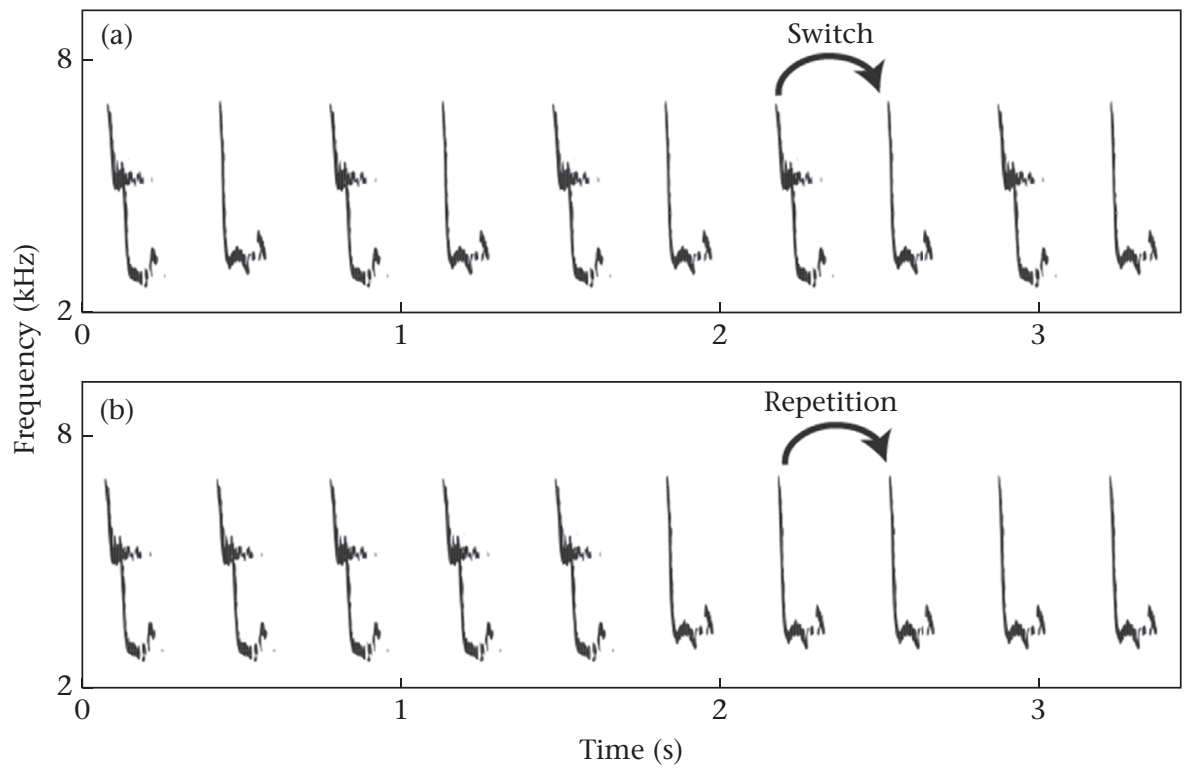

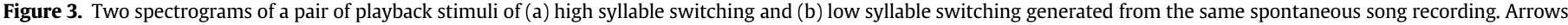
indicate transitions between syllables. FFT window length 512 samples, window overlap $80 \%$, window type=Hamming.

the simulated intruder as in natural interactions of some species (Catchpole, 1989). Therefore, we measured the latency to start singing again as the time (s) elapsed from the end of the playback to the beginning of the first song after the playback. This was measured in the recordings afterwards and not during playback in the field. In situ, one of the observers blind to the treatment measured the approach response by dictating into the microphone every time the bird went across the $1 \mathrm{~m}$ perimeter around the speaker (Leitao et al., 2006; Slater \& Catchpole, 1990). Both of these behaviours have been used extensively to evaluate response strength (Burt et al., 2001; Krebs, Ashcroft, \& Van Orsdol, 1981; Linhart et al., 2013) and are found during natural territorial conflicts (Catchpole, 1977).

In addition, we analysed the songs produced pre- and postplayback using spectrograms (window size 1024, 80\% overlap, Hamming window). We defined a song as any group of at least three syllables separated from the subsequent syllable by more than $0.5 \mathrm{~s}$, which is 1.5 times the average syllable interval within a song obtained from a previous study in this species (Linhart et al., 2013). We measured song length (s) from the beginning of the first syllable to the end of the last syllable and subsequently measured song interval as the time between the beginning of the song and the beginning of the next song. The song interval was measured only for the first nine songs since the 10th song was followed by the playback stimulus and all birds then stopped singing. The song interval minus the song length gives the gap between songs. We then calculated song output as song length as a proportion of the song interval. Values above 0.5 thus represent songs longer than gaps whereas values below 0.5 represent gaps shorter than songs per song interval. We also calculated syllable rate as the number of syllables/s within songs. We used song output and syllable rate to evaluate song response to playback treatments 
since they are known to be relevant during singing contests in this and a closely related species (Linhart et al., 2013; Szymkowiak \& Kuczyński, 2017). In experiment 1, we also measured syllable diversity as the number of different syllable types per song. In experiment 2 we instead measured syllable switching as a binomial variable with only two possible outcomes. If the bird switched between syllable types in all transitions throughout the song, the song was marked as 1 . Otherwise, if the bird repeated the same syllable type consecutively (at least once) within the song, it was marked as 0 .

\section{Statistical Analyses}

All statistical analyses were done with the $R$ software ( $R$ Development Core Team, 2016). To measure the behavioural response we used the latency to counter-sing and the approach response. For a single playback exposure, we collected a single value of latency and a single value of approach. To test whether the behavioural response differed significantly between treatments, we used a Wilcoxon signed-rank test because these variables were not normally distributed, and all points were paired.

We analysed the detailed patterns of the singing response among and within phases. Most playback studies estimate a mean value of each song parameter per playback phase. In this study, we observed that postplayback song was highly dynamic, changing rapidly along the 10 songs recorded. This post hoc observation made us explore song variation with the position of a song in the sequence of 10 as a factor using mixed models (Bates, 2010). Before building the models to test our hypotheses, we fitted preliminary models to choose the appropriate structure of song position since some parameters of song presented a clear quadratic temporal pattern postplayback (see Results). We fitted one model for each song parameter using song position as the only fixed effect and the territory identity as a random effect to account for the paired design of the experiment and deal with repeated measurements. These models were fitted on postplayback songs to find out whether a quadratic pattern or a linear pattern was a more suitable distribution for the model (Table 1). We used an information theoretic approach to choose between the two possibilities, with a significance threshold of $\triangle \mathrm{AICC}>7$, where $\triangle \mathrm{AICc}$ is the change in the Akaike information criterion corrected for small sample sizes (Burnham, Anderson, \& Huyvaert, 2011; Table 1).

After determining the right temporal structure, we fitted a mixed-effects model with a three-way full interaction between phase (preplayback versus postplayback), treatment (high versus low diversity or high versus low switching) and song position, for each song trait. Exceptionally, the model of syllable diversity incorporated a fourth factor: the total number of syllables per song to control for the effect of song length on syllable diversity. We included the territory identity as a random effect in these models.

Table 1

Model selection of song position

\begin{tabular}{ll}
\hline Song trait & $\Delta$ AICc \\
\hline Syllable rate & 8.7 \\
Song output & -35.4 \\
Syllable diversity & -11.7 \\
Syllable switching & -1.0 \\
\hline
\end{tabular}

The table gives the $\triangle \mathrm{AICc}$ of the relative difference of the quadratic model with respect to the linear model. Negative values indicate that the quadratic model is preferred. Significance threshold is $\triangle$ AICc -7 (Burnham et al., 2011). Linear model: song trait $\sim$ song position + (1|territory). Quadratic model: song trait $\sim$ song position + song position ${ }^{2}$.
The effect of phase and treatment allowed us to test our two predictions: (1) do birds change their song after playback and (2) does the change from preplayback to postplayback differ significantly between treatments? Note that we did not carry out a model selection process since the models are based on the experimental design. For experiment 1 on syllable diversity, we fitted one model for syllable rate, one for song output and a third for syllable diversity. Similarly, for experiment 2 on syllable switching, we fitted one model for syllable rate, one for song output and, in this case, a third for syllable switching. Syllable rate, song output and syllable diversity fitted a normal distribution whereas syllable switching fitted a binomial distribution.

We validated all models visually by using diagnostic plots to check for violations of the assumptions of normality and homoscedasticity of the residuals. For the linear mixed models, we estimated $P$ values via the Satterthwaite's degrees of freedom method (Kuznetsova, Brockhoff, \& Christensen, 2016) whereas in the binomial model we used the Wald $Z$ test to estimate $P$ values (Bolker et al., 2009).

\section{Ethical Note}

The study adheres to the ASAB/ABS Guidelines for the Use of Animals in Research. The birds were never caught. Each playback test lasted an average \pm SE of $8.83 \pm 0.2$ min causing some disturbance to the birds that responded as if there was an intruder in their territory. We can confirm that none of the birds left the territory after the first playback exposure since we encountered them the following day to carry out the second test of the trial.

\section{RESULTS}

The complete sample was 43 individuals, 22 assigned to experiment 1 on syllable diversity and 21 to experiment 2 on syllable switching. Every individual was tested twice, one for each treatment yielding a total of 86 playback tests. Within each test we collected 20 songs, 10 pre- and 10 postplayback, which resulted in a total of 1720 songs analysed.

\section{Experiment 1: Syllable Diversity}

In experiment 1, contrasting responses to high- and lowdiversity song treatments, we did not find any significant differences in the syllable rate, song output or syllable diversity between treatments as shown by the estimates for the interaction between phase and treatment in the model outputs of Table 2 (Fig. 4a, b, c). Regardless of treatment, we found that syllable rate and song output changed significantly from the pre- to the postplayback phase as indicated by the effect of phase in the model outputs of Table 2. The effect of phase indicates the estimated difference in syllable rate from pre- to postplayback at the intercept (song position $=0$ ). This means that the initial values of syllable rate after playback were significantly higher than preplayback values regardless of treatment (Fig. 4a). After that initial increase, syllable rate decreased significantly over time in a linear fashion as indicated for the estimate of the interactions between phase and song position (see syllable rate model, Table 2). Unlike syllable rate, song output after playback was significantly lower than preplayback values at the intercept, regardless of treatment (see estimate of phase on song output model in Table 2). Song output increased significantly during the postplayback phase following a parabolic curve (see the estimates of the interaction between phase and song position in Table 2). Finally, the subjects themselves did not change their syllable diversity significantly from before to after playback, 
Table 2

Model results of experiment 1 on syllable diversity

\begin{tabular}{|c|c|c|c|c|c|c|}
\hline Parameters & Fixed effects & Estimate & SE & $d f$ & $t$ & $P$ \\
\hline \multirow[t]{8}{*}{ Syllable rate } & Intercept & 2.860 & 0.035 & 50.1 & 82.73 & $<0.001$ \\
\hline & Phase (post) & 0.318 & 0.030 & 851 & 10.61 & $<0.001$ \\
\hline & Treatment (low) & -0.027 & 0.030 & 851 & -0.904 & 0.366 \\
\hline & Song position & $<0.001$ & 0.003 & 851 & 0.122 & 0.903 \\
\hline & Phase (post)*Treatment (low) & 0.028 & 0.042 & 851 & 0.671 & 0.503 \\
\hline & Phase (post)*Song position & -0.023 & 0.003 & 851 & -4.863 & $<0.001$ \\
\hline & Treatment (low)*Song position & 0.005 & 0.005 & 851 & 0.996 & 0.320 \\
\hline & Phase (post)*Treatment (low)*Song position & -0.002 & 0.007 & 851 & -0.335 & 0.738 \\
\hline \multirow[t]{12}{*}{ Song output } & Intercept & 0.356 & 0.045 & 551 & 7.902 & $<0.001$ \\
\hline & Phase (post) & -0.179 & 0.060 & 759 & -2.993 & 0.003 \\
\hline & Treatment (low) & 0.067 & 0.060 & 759 & 1.126 & 0.260 \\
\hline & Song position & 0.019 & 0.019 & 759 & 0.978 & 0.328 \\
\hline & Song position ${ }^{2}$ & -0.001 & 0.002 & 759 & -0.706 & 0.480 \\
\hline & Phase (post)*Treatment (low) & 0.024 & 0.085 & 759 & 0.284 & 0.777 \\
\hline & Phase (post)*Song position & 0.114 & 0.027 & 759 & 4.133 & $<0.001$ \\
\hline & Phase (post)*Song position ${ }^{2}$ & -0.010 & 0.003 & 759 & -3.712 & $<0.001$ \\
\hline & Treatment (low)*Song position & -0.041 & 0.027 & 759 & -1.477 & 0.140 \\
\hline & Treatment (low)*Song position ${ }^{2}$ & 0.003 & 0.003 & 759 & 1.207 & 0.228 \\
\hline & Phase (post)*Treatment (low): Song position & -0.011 & 0.039 & 759 & -0.277 & 0.782 \\
\hline & Phase (post)*Treatment (low): Song position ${ }^{2}$ & 0.002 & 0.004 & 759 & 0.559 & 0.576 \\
\hline \multirow[t]{9}{*}{ Syllable diversity } & Intercept & 3.459 & 0.144 & 136.6 & 23.97 & $<0.001$ \\
\hline & Phase (post) & -0.264 & 0.170 & 805.4 & -1.550 & 0.121 \\
\hline & Treatment (low) & -0.221 & 0.169 & 805.3 & -1.313 & 0.189 \\
\hline & Number of syllables & 0.358 & 0.030 & 805.3 & 0.023 & $<0.001$ \\
\hline & Phase (post)*Treatment (low) & 0.314 & 0.239 & 825.3 & 11.92 & 0.190 \\
\hline & Phase (post)*Song position & $<0.001$ & 0.019 & 805.2 & 1.312 & 0.982 \\
\hline & Phase (post)*Song position & 0.020 & 0.019 & 805.3 & 0.701 & 0.310 \\
\hline & Treatment (low)*Song position & 0.026 & 0.027 & 805.2 & 0.947 & 0.344 \\
\hline & Phase (post)*Treatment (low)*Song position & -0.038 & 0.039 & 805.3 & -0.990 & 0.323 \\
\hline
\end{tabular}

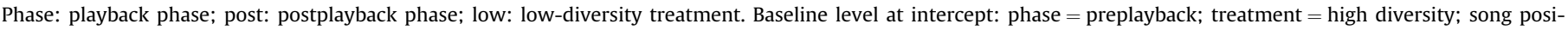
tion $=0$. Territory ID was a random effect. Significant $P$ values are shown in bold.

nor was there any significant difference between treatments or along the response (see syllable diversity model in Table 2).

We found a significant difference between treatments in both latency and approach. The latency to counter-sing after playback was significantly shorter after the high-diversity treatment than after the low-diversity treatment (Wilcoxon signed-rank test: $V=59, P=0.028,2.5 \%$ confidence interval, $\mathrm{CI}=-19.19,97.5 \% \mathrm{CI}=-$ 1.25; Fig. 4d). In line with these results, individuals also spent significantly more time within $1 \mathrm{~m}$ of the speaker during the highdiversity treatment than during the low-diversity treatment (Wilcoxon signed-rank test: $V=133, P<0.001,2.5 \% \mathrm{CI}=6.50,97.5 \%$ $\mathrm{CI}=11.50$; Fig. 4e).

\section{Experiment 2: Syllable Switching}

In experiment 2, testing the role of syllable switching, we did not find any significant differences in syllable rate, song output or syllable switching between high- and low-switching treatments (Fig. 5a, b, c, Table 3). We found that syllable rate and song output followed the same pattern as in experiment 1, except that in this case song output was not significantly lower after than before playback at the intercept (see estimate of phase in models in Table 3). Birds did not modify syllable switching from before to after playback significantly (see estimates of the effect of phase in the syllable-switching model in Table 3). However, syllable switching did vary after playback, increasing significantly over subsequent songs (see estimates for the interaction between phase and song position in Table 3). The model shows the increase in switching along the response as higher after the high-switching treatment than after the low-switching treatment, but the difference is not significant (slope difference $=-0.19, P=0.12$; see estimates for the interaction between phase, treatment and song position in Table 3).
We found no differences between treatments in either the latency to counter-sing (Wilcoxon signed-rank test: $V=98$, $P=0.562,2.5 \% \mathrm{CI}=-10.85,97.5 \% \mathrm{CI}=4.30$; Fig. $5 \mathrm{~d}$ ) or the approach response (Wilcoxon signed-rank test: $V=65, P=0.383,2.5 \% \mathrm{CI}=$ 12.00, 97.5\% $\mathrm{CI}=8.50$; Fig. 5e).

\section{DISCUSSION}

We tested the communicative value of syllable diversity and syllable switching in the common chiffchaff during territorial contests. Our first experiment showed that they perceived variation in syllable diversity and responded more strongly to higher syllable diversity. However, the syllable diversity of responding birds did not change significantly from pre- to postplayback, suggesting it is a fixed trait. In contrast, birds changed their syllable rate and song output significantly after playback, regardless of treatment (Linhart et al., 2012, 2013). Our second experiment showed no evidence for perception of variation in syllable switching: neither the behavioural response nor the song features varied significantly between high- and low-switching treatments. In this case, syllable rate, but not song output, changed significantly from before to after playback. Even though syllable switching did not change significantly from before to after playback, it increased significantly within the series of songs after the playback, suggesting it is a dynamic trait.

\section{Syllable Diversity Signalling Quality}

The results of the first experiment support our predictions that (1) chiffchaffs are able to discriminate between songs of different syllable diversity and that (2) they respond more aggressively towards high-diversity than low-diversity songs. Chiffchaffs responded faster after the high-diversity than after the low-diversity treatment and seven of eight males spent more time searching 

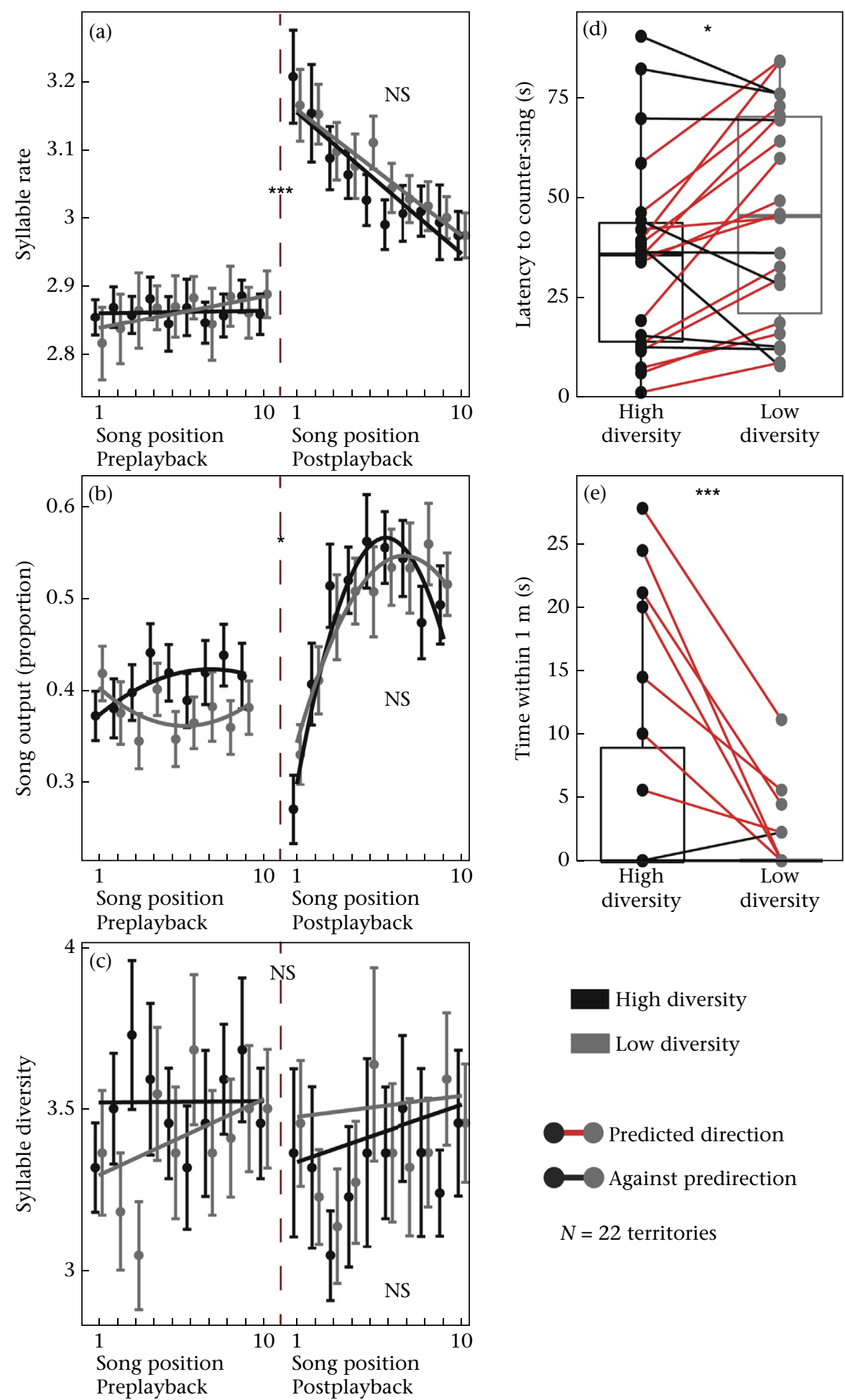

High diversity

Low diversity

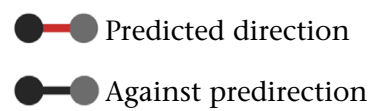

$N=22$ territories

Figure 4. Results of acoustic and behavioural variation in experiment 1 on the role of syllable diversity. (a) Syllable rate (number of syllables/s), (b) song output (song length as a proportion of the time between the beginning of the song and the beginning of the next song) and (c) syllable diversity (number of syllable types in a song) in relation to song position (i.e. the position of the song in the sequence of 10 songs recorded). Points and error bars represent the mean and standard error of all individuals per song, whereas lines indicate the predicted values derived from the models. The dashed line marks the playback exposure. Significance is shown for the contrast between pre- and postplayback (on the dashed line) and for the contrast between treatments postplayback. (d, e) Behavioural variables measured during the response to playbacks: (d) latency to counter-sing and (e) approach response (time spent within $1 \mathrm{~m}$ of the speaker). The lines link the same individual in each treatment. The predicted direction was a stronger response towards the high-diversity treatment. The box plots show the median and 25th and 75th percentiles; the whiskers indicate the values within 1.5 times the interquartile range. ${ }^{* * *} P<0.001 ; * P<0.05$. 

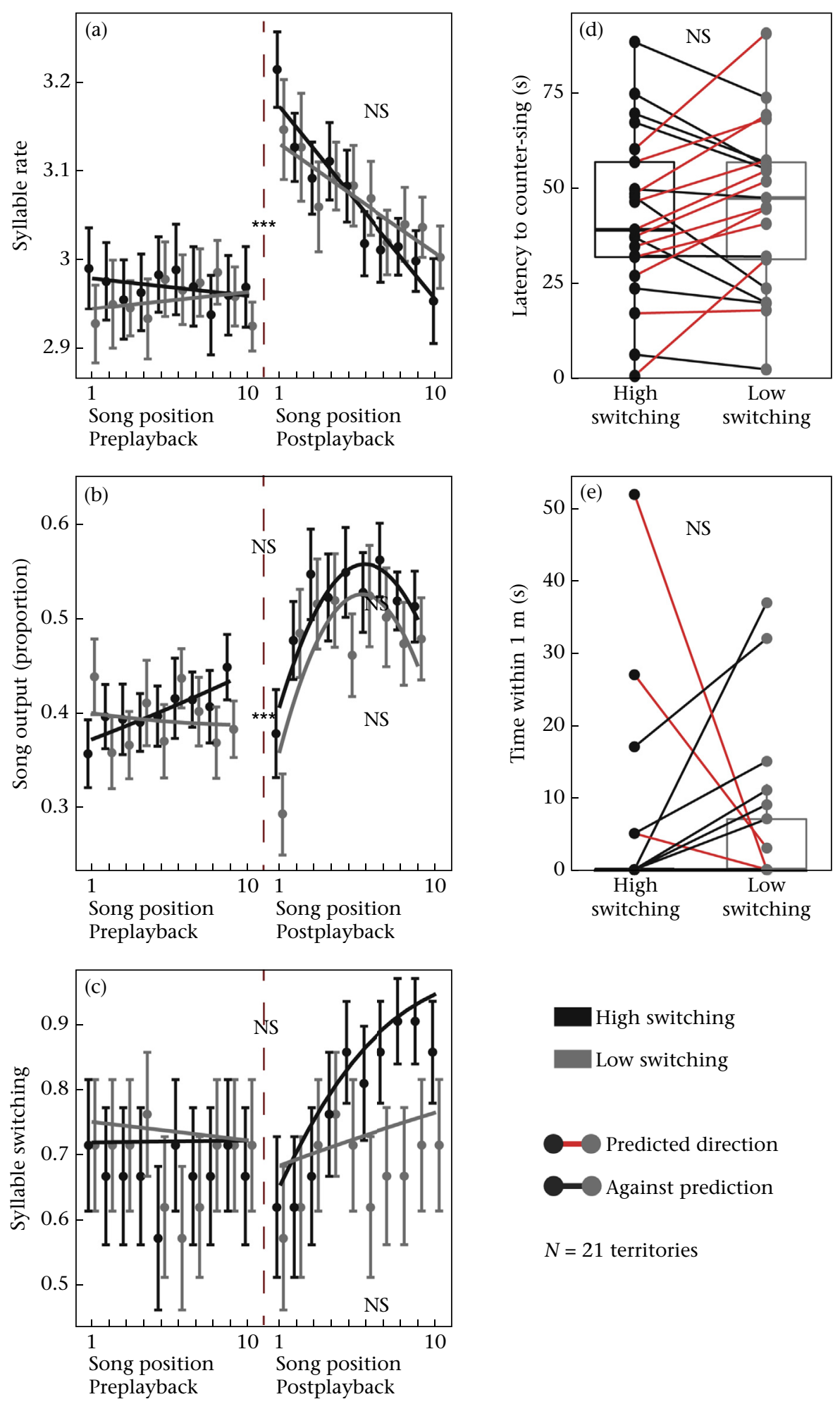

High switching

Low switching

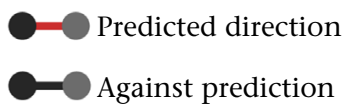

$N=21$ territories

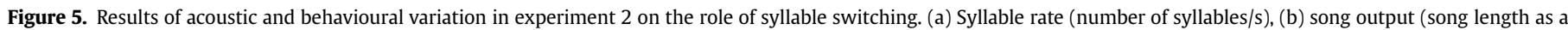

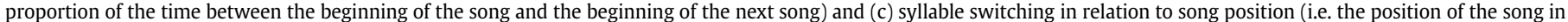

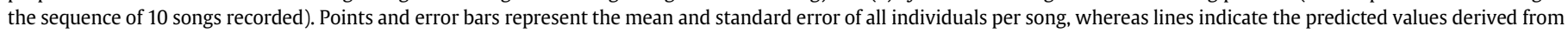

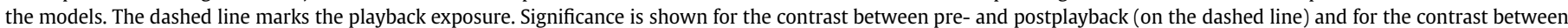

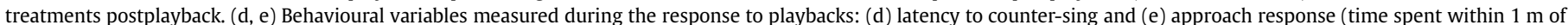

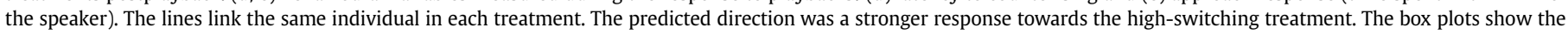
median and 25th and 75th percentiles; the whiskers indicate the values within 1.5 times the interquartile range. $* * * P<0.001$. 
Table 3

Model results of experiment 2 on syllable switching

\begin{tabular}{|c|c|c|c|c|c|c|}
\hline Parameters & Fixed effects & Estimate & SE & $d f$ & $t / z$ & $P$ \\
\hline \multirow[t]{8}{*}{ Syllable rate } & Intercept & 2.981 & 0.037 & 34 & 79.84 & $<0.001$ \\
\hline & Phase (post) & 0.215 & 0.026 & 812 & 8.171 & $<0.001$ \\
\hline & Treatment (low) & -0.039 & 0.026 & 812 & -1.473 & 0.141 \\
\hline & Song position & -0.002 & 0.003 & 812 & -0.731 & 0.465 \\
\hline & Phase (post)*Treatment (low) & -0.014 & 0.037 & 812 & -0.364 & 0.716 \\
\hline & Phase (post)*Song position & -0.024 & 0.003 & 812 & -5.220 & $<0.001$ \\
\hline & Treatment (low)*Song position & 0.004 & 0.004 & 812 & 1.018 & 0.309 \\
\hline & Phase (post)*Treatment (low)*Song position & 0.006 & 0.006 & 812 & 1.037 & 0.300 \\
\hline \multirow{12}{*}{ Song output } & Intercept & 0.365 & 0.050 & 563 & 7.299 & $<0.001$ \\
\hline & Phase (post) & -0.027 & 0.067 & 724 & -0.406 & 0.685 \\
\hline & Treatment (low) & 0.038 & 0.067 & 724 & 0.564 & 0.573 \\
\hline & Song position & 0.007 & 0.022 & 724 & 0.314 & 0.753 \\
\hline & Song position ${ }^{2}$ & 0.000 & 0.002 & 724 & 0.043 & 0.966 \\
\hline & Phase (post)*Treatment (low) & -0.095 & 0.095 & 724 & -1.003 & 0.316 \\
\hline & Phase (post)*Song position & 0.067 & 0.031 & 724 & 2.180 & 0.030 \\
\hline & Phase (post)*Song position ${ }^{2}$ & -0.006 & 0.003 & 724 & -2.106 & 0.036 \\
\hline & Treatment (low)*Song position & -0.010 & 0.031 & 724 & -0.317 & 0.751 \\
\hline & Treatment (low)*Song position ${ }^{2}$ & 0.000 & 0.003 & 724 & 0.016 & 0.987 \\
\hline & Phase (post)*Treatment (low): Song position & 0.021 & 0.044 & 724 & 0.472 & 0.637 \\
\hline & Phase (post)*Treatment (low): Song position ${ }^{2}$ & -0.001 & 0.004 & 724 & -0.270 & 0.787 \\
\hline \multirow[t]{8}{*}{ Syllable switching } & Intercept & 0.937 & 0.440 & & 2.128 & 0.033 \\
\hline & Phase (post) & -0.555 & 0.510 & & -1.089 & 0.276 \\
\hline & Treatment (low) & 0.180 & 0.498 & & 0.361 & 0.718 \\
\hline & Song position & 0.002 & 0.056 & & 0.029 & 0.977 \\
\hline & Phase (post)*Treatment (low) & 0.163 & 0.711 & & 0.230 & 0.818 \\
\hline & Phase (post)*Song position & 0.250 & 0.069 & & 2.784 & $<0.001$ \\
\hline & Treatment (post)*Song position & -0.018 & 0.080 & & -0.225 & 0.822 \\
\hline & Phase (post)*Treatment (low)*Song position & -0.187 & 0.120 & & -1.556 & 0.120 \\
\hline
\end{tabular}

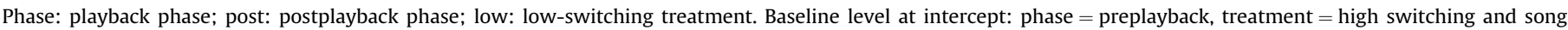
position $=0$. Territory ID was a random effect. Significant $P$ values are shown in bold.

within $1 \mathrm{~m}$ of the speaker. The lack of variation in syllable diversity with context, from before to after or during the response to the two treatments, suggests that this is a relatively fixed trait. Syllable diversity is therefore more likely to signal male quality than motivation to escalate into a fight. The absence of differences in the singing response between treatments might be due to a ceiling effect (Martin, Bateson, \& Bateson, 1993). While such vocal interactions normally start at the territory border (Järvi, Radesäter, \& Jakobsson, 1980), our playbacks were inside the subject's territory and may have triggered high-intensity responses independent of the potential variation in relative threat level from the simulated intruder (Martin et al., 1993; McGregor, 2000).

In line with previous authors (Catchpole, 1977; Leitao et al., 2006; Searcy \& Beecher, 2009), we suggest that birds respond more aggressively to high-diversity songs because they perceive the simulated intruder as a bigger threat. It may be the case that individual chiffchaffs acquire a certain repertoire of syllables depending on early life conditions (Nowicki et al., 1998; Nowicki, Searcy, \& Peters, 2002), and syllable diversity therefore seems a relatively fixed trait conveying information about individual quality (Rivera-Gutierrez, Pinxten, \& Eens, 2010). Alternatively, syllable diversity could be an age-related trait associated with experience in open-ended learner species. In the willow warbler, Phylloscopus trochilus, a sibling species, there is longitudinal and cross-sectional evidence for an age-related increase in syllable repertoire, at least for the first 2 years (Gil et al., 2001; Järvi, 1983). Similar findings have been reported for unrelated species (Balsby, 2000; Mountjoy \& Lemon, 1995). In both ways, through variation in early age development or in survival to a lifetime peak performance, syllable diversity can play a role in signalling mate or competitor quality during territorial interactions (Kokko, 1997; Manning, 1989).

\section{Switching Syllables to Signal Motivation?}

We found no direct evidence that birds discriminated between high- and low-switching songs, nor that switching changed immediately from before to after our playback. These results from our planned comparisons suggested that this trait is relatively fixed and does not play a role in communicating sender quality or motivation to escalate into a fight. However, the birds tended to increase syllable switching during the response to playback. A difference in slopes between the two treatments would have suggested that the birds could discriminate between high and low switching rates after all, but the slopes were not significantly different. Nevertheless, excluding the ability to perceive switching rates seems premature and the results open the possibility that it is a dynamic trait that signals some sort of motivation in combination with other song traits.

An important aspect of syllable switching to consider for the chiffchaff is the role it may play in species recognition (da Prato \& da Prato, 1983; Fulford, 2017; Helbig et al., 1996; Salomon, 1989). Chiffchaffs in our study typically sang highly versatile songs by default: in 860 songs recorded during the preplayback phase in both experiments, 578 did not have a single repetition. It was also rare to find more than two repetitions within a song. The geographical distribution of the common chiffchaff overlaps in parts of its range with two species with which it can hybridize: the willow warbler and the Iberian chiffchaff, Phylloscopus ibericus. Both species have similar song elements but much lower syllable switching rates. This indicates that syllable switching may be a fundamental feature of the species-specific song and may play a role in motivational signalling potentially bounded by species recognition (Doutrelant, Aubin, Hitier, \& Lambrechts, 1998; Price, 1998; Ryan \& Rand, 1993). 


\section{Playback Response Patterns}

To our knowledge, this is the first time that a playback experiment has been analysed and presented with such detailed temporal resolution, showing how song in response to playback changes quickly over time. We used the model estimates to calculate when each song trait met its maximum value during the singing response. We found that syllable rate rose very quickly at the beginning of the playback response with its maximum in song 1 (Figs. 4a and 5a). After the first song, syllable rate decreased gradually in a linear fashion. This observation could be crucial for a full understanding of its communication value and needs to be taken into consideration when using bins of song to compare variation before and after playback (see de Kort, Eldermire, Valderrama, Botero, \& Vehrencamp, 2009; Searcy \& Nowicki, 2000). Other song traits such as song output also changed during the postplayback phase but they followed a quadratic pattern rather than a linear change over time. In contrast to syllable rate, the first song of the response had the lowest output of the entire response, probably lower than preplayback values. Over the postplayback phase, song output increased following a parabolic curve with its maximum value in song 6 (see Figs. 4b and 5b). Even though average song output was similar before and after playback, the behaviour of the bird was obviously not the same.

Another important insight from our detailed analysis is that different song traits followed different patterns during the response. As an example, syllable rate, song output and syllable switching increased significantly after playback, but all three were highest at different times. At song 1, syllable rate was at its highest, whereas song output dropped to its minimum. Then, song output increased reaching the maximum point at song 6 whereas syllable switching increased more gradually reaching the maximum point at song 10 (Fig. 5c). We propose that different traits may be involved in different stages of escalation and play a complementary role in conflict (Dabelsteen \& Pedersen, 1990; Hof \& Podos, 2013). The complexity and subtlety of the combined changes in song over time provide new insights into vocal interactions among territorial birds. Our results suggest that the exchange of information between two communicating birds may go well beyond what has so far been assumed and future studies therefore need to adjust the duration of response assessment and the resolution of analyses to avoid missing relevant information in the behavioural response.

\section{Conclusion}

Our results revealed that syllable diversity is a relatively fixed trait in chiffchaffs and that variation among individuals is perceived by conspecifics and probably communicates some sort of male quality. We were unable to confirm perception of variation in syllable switching, but changes in switching after playback suggested that it may be a dynamic trait contributing to motivational signalling together with other changing song parameters. Furthermore, our analyses revealed in unprecedented detail how complex and subtle vocal communication may be among interacting birds. We therefore support the increased temporal resolution of analysis as used in the current investigation for future playback studies. We expect that this may yield many new insights and potentially reveal levels of communication among birds, or individuals of other taxa, well beyond our current understanding.

\section{Acknowledgments}

We are grateful to Katharina Riebel and Andrew Wolfenden for their comments on the design and planning of this study. We also want to acknowledge the help from other students and staff of the
Behavioral Biology department at the Institute of Biology Leiden (IBL) during lab meetings and open discussions. We are grateful to Diego Gil for his useful comments on the manuscript. We also thank the anonymous referees for their helpful comments and suggestions.

\section{References}

Airey, D. C., Castillo-Juarez, H., Casella, G., Pollak, E. J., \& DeVoogd, T. J. (2000) Variation in the volume of zebra finch song control nuclei is heritable: developmental and evolutionary implications. Proceedings of the Royal Society of London Series B: Biological Sciences, 267, 2099-2104.

Bairlein, F., Alström, P., Aymí, R., Clement, P., Dyrcz, A., Gargallo, G., et al. (2006) Family Sylviidae (Old World warblers) (Vol. 11). Barcelona, Spain: Lynx Edicions.

Balsby, T. J. S. (2000). Song activity and variability in relation to male quality and female choice in whitethroats Sylvia communis. Journal of Avian Biology, 31(1), 56-62.

Bates, D. M. (2010). Ime4: Mixed-effects modeling with R. http://lme4.r-forge.r-project.org/book.

Bolker, B. M., Brooks, M. E., Clark, C. J., Geange, S. W., Poulsen, J. R., Stevens, M. H. H. et al. (2009). Generalized linear mixed models: A practical guide for ecology and evolution. Trends in Ecology \& Evolution, 24(3), 127-135.

Brumm, H., Zollinger, S. A., \& Slater, P. J. B. (2009). Developmental stress affects song learning but not song complexity and vocal amplitude in zebra finches. Behavioral Ecology and Sociobiology, 63, 1387-1395.

Burnham, K. P., Anderson, D. R., \& Huyvaert, K. P. (2011). AIC model selection and multimodel inference in behavioral ecology: Some background, observations, and comparisons. Behavioral Ecology and Sociobiology, 65(1), 23-35.

Burt, J. M., Campbell, S. E., \& Beecher, M. D. (2001). Song type matching as threat: A test using interactive playback. Animal Behaviour, 62(6), 1163-1170.

Catchpole, C. K. (1977). Aggressive responses of male sedge warblers (Acrocephalus schoenobaenus) to playback of species song and sympatric species song, before and after pairing. Animal Behaviour, 25(MAY), 489-496.

Catchpole, C. K. (1989). Responses of male sedge warblers to playback of different repertoire sizes. Animal Behaviour, 37, 1046-1047.

Catchpole, C. K., \& Slater, P. J. B. (2003). Bird song: biological themes and variations. New York, NY: Cambridge University Press.

Cramp, S. (1992). The birds of the Western Palearctic. Handbook of the bird of Europe, the Middle East and North Africa (Vol. 6). Oxford, U.K.: Oxford University Press (Warblers).

Collins, S. (2004). Vocal fighting and flirting: the functions of birdsong. In P. Marler; \& H. Slabbekoorn (Eds.), Nature's music: the science of birdsong (pp. 39-79). San Diego, CA: Elsevier Academic Press.

Dabelsteen, T., \& Pedersen, S. B. (1990). Song and information about aggressive responses of blackbirds, Turdus merula: Evidence from interactive playback experiments with territory owners. Animal Behaviour, 40(6), 1158-1168.

da Prato, S., \& da Prato, E. (1983). Probable hybridisation between chiffchaff and willow warbler. British Birds, 76, 248-251.

de Kort, S. R., Eldermire, E. R. B., Valderrama, S., Botero, C. A., \& Vehrencamp, S. L. (2009). Trill consistency is an age-related assessment signal in banded wrens. Proceedings of the Royal Society B: Biological Sciences, 276(1665), 2315-2321.

Doutrelant, C., Aubin, T., Hitier, S., \& Lambrechts, M. M. (1998). Two distinct song populations of blue tit Parus caeruleus in the French Mediterranean. Bioacoustics, 9(1), 1-16.

Doutrelant, C., Blondel, J., Perret, P., \& Lambrechts, M. M. (2000). Blue tit song repertoire size, male quality and interspecific competition. Journal of Avian Biology, 360-366.

Fulford, T. (2017). Do Willow Warblers 'chiff-chaff when they are cross? British Birds, 110, 249-308.

Galeotti, P., Saino, N., Perani, E., Sacchi, R., \& Møller, A. R. (2001). Age-related song variation in male barn swallows. Italian Journal of Zoology, 68(4), 305-310.

Galeotti, P., Saino, N., Sacchi, R., \& Møller, A. P. (1997). Song correlates with social context, testosterone and body condition in male barn swallows. Animal Behaviour, 53(4), 687-700.

Gil, D., Cobb, J. L. S., \& Slater, P. J. B. (2001). Song characteristics are age dependent in the willow warbler, Phylloscopus trochilus. Animal Behaviour, 62, 689-694.

Hall, M. L., Kingma, S. A., \& Peters, A. (2013). Male songbird indicates body size with low-pitched advertising songs. PloS One, 8(2). e56717.

Helbig, A. J., Martens, J., Seibold, I., Henning, F., Schottler, B., \& Wink, M. (1996) Phylogeny and species limits in the palaearctic chiffchaff Phylloscopus collybitc complex: Mitochondrial genetic differentiation and bioacoustic evidence. Ibis, 138(4), 650-666.

Hesler, N., Mundry, R., Sacher, T., Coppack, T., Bairlein, F., \& Dabelsteen, T. (2012). Song repertoire size correlates with measures of body size in Eurasian blackbirds. Behaviour, 149(6), 645-665.

Hiebert, S. M., Stoddard, P. K., \& Arcese, P. (1989). Repertoire size, territory acquisition and reproductive success in the song sparrow. Animal Behaviour, 37, 266-273.

Hof, D., \& Podos, J. (2013). Escalation of aggressive vocal signals: A sequential playback study. Proceedings of the Royal Society B: Biological Sciences, 280(1768), 20131553. 
Järvi, T. (1983). The evolution of song versatility in the willow warbler Phylloscopus trochilus: A case of evolution by intersexual selection explained by the' female's choice of the best mate'. Ornis Scandinavica, 14(2), 123-128.

Järvi, T., Radesäter, T., \& Jakobsson, S. (1980). The song of the willow warbler Phylloscopus trochilus with special reference to singing behaviour in agonistic situations. Ornis Scandinavica, 11(3), 236-242.

Kokko, H. (1997). Evolutionarily stable strategies of age-dependent sexual advertisement. Behavioral Ecology and Sociobiology, 41(2), 99-107.

Kramer, H. G., Lemon, R. E., \& Morris, M. J. (1985). Song switching and agonistic stimulation in the song sparrow (Melospiza melodia): Five tests. Animal Behaviour, 33(1), 135-149.

Krebs, J. R., Ashcroft, R., \& Van Orsdol, K. (1981). Song matching in the great tit Parus major L. Animal Behaviour, 29(3), 918-923.

Kroodsma, D. (2004). The diversity and plasticity of birdsong. In P. Marler, \& H. Slabbekoorn (Eds.), Nature's music: the science of birdsong (pp. 108-131). San Diego, CA: Elsevier Academic Press.

Kroodsma, D. E. (1990). Using appropriate experimental designs for intended hypotheses in 'song'playbacks, with examples for testing effects of song repertoire sizes. Animal Behaviour, 40(6), 1138-1150.

Kroodsma, D. E., \& Byers, B. E. (1991). The function(s) of bird song. American Zoologist, 31(2), 318-328.

Kuznetsova, A., Brockhoff, P., \& Christensen, R. (2016). Tests in linear mixed effects models version. https://cran.r-project.org/web/packages/lmerTest/lmerTest. pdf.

Leitao, A., ten Cate, C., \& Riebel, K. (2006). Within-song complexity in a songbird is meaningful to both male and female receivers. Animal Behaviour, 71, 1289-1296.

Lemon, R. E., \& Kramer, H. G. (1983). Dynamics of territorial singing between neighboring song sparrows (Melospiza melodia). Behaviour, 85(3-4) $198-223$.

Linhart, P., Jaška, P., Petrusková, T., Petrusek, A., \& Fuchs, R. (2013). Being angry, singing fast? Signalling of aggressive motivation by syllable rate in a songbirc with slow song. Behavioural Processes, 100, 139-145.

Linhart, P., Slabbekoorn, H., \& Fuchs, R. (2012). The communicative significance of song frequency and song length in territorial chiffchaffs. Behavioral Ecology, 23(6), 1338-1347.

Manning, J. T. (1989). Age-advertisement and the evolution of the peacock's train. Journal of Evolutionary Biology, 2(5), 379-384.

Martin, P., Bateson, P. P. G., \& Bateson, P. (1993). Measuring behaviour: an introductory guide. Cambridge, U.K.: Cambridge University Press.

Mazzoni, D., \& Dannenberg, R. (2014). Audacity. https://www.audacityteam.org/.

McGregor, P. K. (1988). Song length and 'male quality'in the chiffchaff. Animal Behaviour, 36(2), 606-608.

McGregor, P. K., Catchpole, C. K., Dabelsteen, T., Falls, J. B., Fusani, L., Gerhardt, H. C., Gilbert, F., Horn, A. G., Klump, G. M., \& Kroodsma, D. E. (1992). Design of playback experiments: the Thornbridge Hall NATO ARW consensus. In P. K. McGregor (Ed.), Playback and studies of animal communication (pp. 1-9). New York, NY: Springer.

McGregor, P. K. (2000). Playback experiments: Design and analysis. Acta Ethologica, $3(1), 3-8$.

Mountjoy, D. J., \& Lemon, R. E. (1991). Song as an attractant for male and female European starlings, and the influence of song complexity on their response. Behavioral Ecology and Sociobiology, 28(2), 97-100.
Mountjoy, J. D., \& Lemon, R. E. (1995). Extended song learning in wild European starlings. Animal Behaviour, 49(2), 357-366.

Nowicki, S., Peters, S., \& Podos, J. (1998). Song learning, early nutrition and sexual selection in songbirds. American Zoologist, 38(1), 179-190.

Nowicki, S., Searcy, W., \& Peters, S. (2002). Brain development, song learning and mate choice in birds: A review and experimental test of the 'nutritional stress hypothesis'. Journal of Comparative Physiology, 188(11-12), 1003-1014.

Otter, K. A., Ratcliffe, L., Njegovan, M., \& Fotheringham, J. (2002). Importance of frequency and temporal song matching in black-capped chickadees: Evidence from interactive playback. Ethology, 108(2), 181-191.

Pfaff, J. A., Zanette, L., MacDougall-Shackleton, S. A., \& MacDougall-Shackleton, E. A. (2007). Song repertoire size varies with HVC volume and is indicative of male quality in song sparrows (Melospiza melodia). Proceedings of the Royal Society B: Biological Sciences, 274(1621), 2035-2040.

Price, T. (1998). Sexual selection and natural selection in bird speciation. Philosophical Transactions of the Royal Society of London. Series B: Biological Sciences, 353(1366), 251-260.

R Development Core Team. (2016). R: A language and environment for statistical computing. Vienna, Austria: R Foundation for Statistical Computing.

Ripmeester, E. A., De Vries, A. M., \& Slabbekoorn, H. (2007). Do blackbirds signal motivation to fight with their song? Ethology, 113, 1021-1028.

Rivera-Gutierrez, H. F., Pinxten, R., \& Eens, M. (2010). Multiple signals for multiple messages: Great tit, Parus major, song signals age and survival. Animal Behaviour, 80(3), 451-459.

Rodrigues, M. (1996). Song activity in the chiffchaff: Territorial defence or mate guarding? Animal Behaviour, 51(3), 709-716.

Ryan, M. J., \& Rand, A. S. (1993). Species recognition and sexual selection as a unitary problem in animal communication. Evolution, 47(2), 647-657.

Salomon, M. (1989). Song as a possible reproductive isolating mechanism between two parapatric forms. The case of the chiffchaffs Phylloscopus c. collybita and P. c. brehmii in the western Pyrenees. Behaviour, 270-290.

Searcy, W. A., \& Andersson, M. (1986). Sexual selection and the evolution of song. Annual Review of Ecology and Systematics, 507-533.

Searcy, W. A., \& Beecher, M. D. (2009). Song as an aggressive signal in songbirds. Animal Behaviour, 78(6), 1281-1292.

Searcy, W. A., \& Nowicki, S. (2000). Male-male competition and female choice in the evolution of vocal signaling. In Y. Espmark, T. Amundsen, \& G. Rosenquist (Eds.) Animal signals: Signalling and signal design in animal communication (pp. 301-315). Trondheim, Norway: Tapir Academic Press.

Searcy, W. A., Nowicki, S., \& Hogan, C. (2000). Song type variants and aggressive context. Behavioral Ecology and Sociobiology, 48(5), 358-363.

Slater, P., \& Catchpole, C. (1990). Responses of the two chaffinch species on Tenerife (Fringilla teydea and F. coelebs tintillon) to playback of the song of their own and the other species. Behaviour, 143-152.

Szymkowiak, J., \& Kuczyński, L. (2017). Song rate as a signal of male aggressiveness during territorial contests in the wood warbler. Journal of Avian Biology, 48(2), 275-283.

Verzijden, M. N., Ripmeester, E. A. P., Ohms, V. R., Snelderwaard, P., \& Slabbekoorn, H. (2010). Immediate spectral flexibility in singing chiffchaffs during experimental exposure to highway noise. The Journal of Experimental Biology, 213, 2575-2581.

Weary, D., Krebs, J., Eddyshaw, R., McGregor, P., \& Horn, A. (1988). Decline in song output by great tits: Exhaustion or motivation? Animal Behaviour, 36(4), 1242-1244. 